\title{
Saudi women driving: images, stereotyping and digital media
}

Article

Accepted Version

Albawardi, A. and Jones, R. H. (2021) Saudi women driving: images, stereotyping and digital media. Visual Communication. ISSN 1741-3214 doi:

https://doi.org/10.1177/14703572211040851 Available at https://centaur.reading.ac.uk/98621/

It is advisable to refer to the publisher's version if you intend to cite from the work. See Guidance on citing.

To link to this article DOI: http://dx.doi.org/10.1177/14703572211040851

Publisher: Sage

All outputs in CentAUR are protected by Intellectual Property Rights law, including copyright law. Copyright and IPR is retained by the creators or other copyright holders. Terms and conditions for use of this material are defined in the End User Agreement.

\section{www.reading.ac.uk/centaur}

\section{CentAUR}

Central Archive at the University of Reading

Reading's research outputs online 


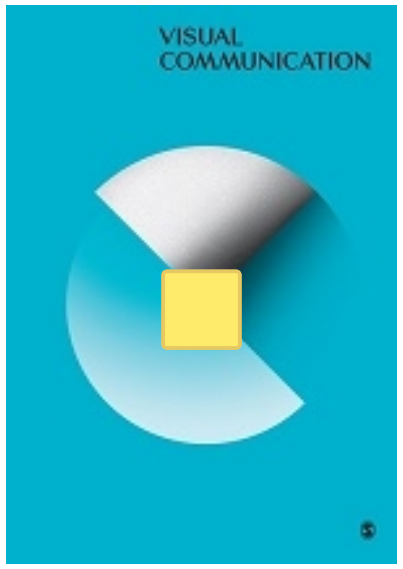

\section{Saudi Women Driving: Images, Stereotyping and Digital Media}

\begin{tabular}{|c|l|}
\hline Journal: & Visual Communication \\
\hline Manuscript ID & VC-20-0040.R3 \\
\hline Keywords: $:$ & $\begin{array}{l}\text { Discourse Analysis, Visual representation, Google Images, Stock } \\
\text { Photography, Stereotyping }\end{array}$ \\
\hline & $\begin{array}{l}\text { This paper examines the representations of Saudi women driving that } \\
\text { circulated shortly after the lifting of the ban and considers the social, } \\
\text { commercial and technological forces that helped to shape those } \\
\text { representations . A corpus of images was collected from two } \\
\text { international image banks -- Getty and Shutterstock-as well as from a } \\
\text { Google Image search. The images were using van Leeuwen's (2008) } \\
\text { visual representation framework, with particular attention to the } \\
\text { similarities and differences between the images available in the image } \\
\text { banks and those that were made prominent in the Google search. In } \\
\text { addition, semantic metadata accompanying these images were also } \\
\text { analysed in order to understand the linguistic constraints that had put on } \\
\text { searches for these images and the ontologies of the issue that they } \\
\text { promoted. Finally, a more detailed analysis was performed on images } \\
\text { that had been appropriated into different contexts such as news stories } \\
\text { and advertisements to investigate how these images were adapted to } \\
\text { support different political, cultural and commercial agendas. Finding s } \\
\text { suggest that images of Saudi women that circulated online } \\
\text { internationally shortly after the lifting of the ban were mostly generic } \\
\text { and decontextualized, creating simplified and trivialized depictions of } \\
\text { gender relations and social change in the Kingdom. The analysis shows } \\
\text { how commercial concerns which influence both the creation of stock } \\
\text { images and the way they are taken up by news organizations and } \\
\text { advertisers can sometimes have the effect of erasing the complexity of } \\
\text { political events and reinforcing the very stereotypes they seem to be } \\
\text { challenging. }\end{array}$ \\
\hline Abstractions \\
\hline
\end{tabular}




\title{
Saudi Women Driving:
}

\section{Images, Stereotyping and Digital Media}

\begin{abstract}
This paper examines the representations of Saudi women driving that circulated shortly after the lifting of the ban and considers the social, commercial and technological forces that helped to shape those representations. A corpus of images was collected from two international image banks -- Getty and Shutterstock - as well as from a Google Image search. The images were using van Leeuwen's (2008) visual representation framework, with particular attention to the similarities and differences between the images available in the image banks and those that were made prominent in the Google search . In addition, semantic metadata accompanying these images were also analysed in order to understand the linguistic constraints that had put on searches for these images and the ontologies of the issue that they promoted. Finally, a more detailed analysis was performed on images that had been appropriated into different contexts such as news stories and advertisements to investigate how these images were adapted to support different political, cultural and commercial agendas. Finding s suggest that images of Saudi women that circulated online internationally shortly after the lifting of the ban were mostly generic and decontextualized, creating simplified and trivialized depictions of gender relations and social change in the Kingdom. The analysis shows how commercial concerns which influence both the creation of stock images and the way they are taken up by news organizations and advertisers can sometimes have the effect of erasing the complexity of political events and reinforcing the very stereotypes they seem to be challenging.
\end{abstract}

Keywords: Discourse Analysis, Visual representation, Google Images, Stock Photography, Stereotyping 


\section{Introduction}

On September 26, 2017, a Saudi royal decree announced the lifting of the 27-year old ban on women driving in the Kingdom. The decree was part of a larger package of reforms known as Vision 2030, spearheaded by the current King's son and Crown Prince, Mohammed bin Salman. Specifically, lifting the ban on women driving was seen as part of a larger goal to increase the number of Saudi women in the workforce.

Minutes after the royal announcement, hundreds of internet users began exchanging texts, images, videos and memes to congratulate or criticize the Saudi women drivers-to-be. Several hashtags such as '\#Women2drive' and '\#SaudiWomenDrive' began trending locally and internationally. On the day that the ban was actually lifted and for some weeks afterwards, national and international news outlets widely reported the historical event.

The coverage of the lifting of the ban on Saudi women driving came in the context of a complex history of representations of women in the media,. In the past, representations of women in Saudi media were characterised by what Sakr (2008: 385) calls 'rigid essentialist rhetoric about "women's nature". More recently, however, representations of women in nontraditional roles in domains such as sport and business has been growing, in parallel with an increased number of Saudi women using the internet (Jarbou, 2018) and a growth in women working in the media (Sakr, 2008). Al-Malki and her colleagues, (2012), for example found that that women in Arab media were generally portrayed in more agentive positions than were Arab women in Western media.

Meanwhile, the representation of Arab women in non-Arab, especially Western, media has been marked by a persistent 'Orientalism' (Said, 1979), which often leads them to be depicted as exoticized, oppressed, powerless and silent (Al-Malki et.al., 2012; Eltantawy 2013; Macdonald, 2006). A key feature of such imagery over the past two centuries has been the veil (Behdad \& Gartlan, 2013). As Eltantawy (2013: 765) notes, '[v]eiling intensifies the image of 
supposed powerlessness, creating the stereotype of a helpless, imprisoned woman in desperate need of Western liberation' (see also Martin Munoz, 2010).

Media images, however, are not static, and stereotypical portrayals of women in Arab countries and of Arab women in other countries circulate beyond national boundaries. Beaulieu \& Roberts (2002), for example, have examined how indigenous Arab and diaspora visual cultures have adapted and reworked European conventions of representing Arab women as a way of resisting the marginalization of voices and subjectivities in Western Orientialism. Such studies suggest that understanding representations of Saudi women both inside and outside of the Kingdom requires attention not just to representations themselves, but also to the ways these representations circulate and interact with one another, and of the local and global discourse processes that go into their production and circulation.

The aim of this paper is to understand something about these local and global discourse processes by examining how the lifting of the ban on women driving in Saudi Arabia was communicated visually to international audiences online in the weeks after it occurred, and particularly how it was mediated though technologies such as stock photography and internet search engines. It seeks to interrogate the role of commercialized images in both challenging and reinforcing stereotypes and to explore how the visual culture of the internet affects how different kinds of people and practices are represented.

\section{Visual Representation and Stereotyping}

For the past two centuries, the development of visual technologies, from photography to digital media, have dramatically altered the way journalists represent people and events and the way audiences understand the world (Chouliaraki, 2009; Newton, 2013; Zelizer, 2005). At the same time, the increasing centrality of photographic images in journalism has highlighted the potential for visual communication to reinforce stereotypes (Ross \& Lester, 2003). Frosh (2002: 
176) explains how photography facilities 'a classificatory dynamic whose goal is the mapping and ordering of the social and natural worlds,' and Sekula (1989) discusses the early role of photography, especially as it was utilised in law enforcement, in defining and classifying 'deviant' bodies and distinguishing them from the bodies of imagined viewers. Since then, there have been numerous studies of the way media images present stereotyped portrayals of a range of social groups including African Americans (Abraham and Appiah, 2006; Poindexter, 2011), Middle Easterners (Jackson, 2011; Kamalipour \& Gerbner, 1997), and women (Kitch, 2009; Otterbacher, et al., 2017). More recently, however, scholars such as Sakr (2008: 387), have highlighted the need to look at the 'practices and processes behind media portrayals' (387) which can often affect the ways images are created, circulated and taken up by the public.

Meanwhile, there has also been increased attention to the way globalization and digital media have led to a homogenization of representations, especially in the news media. Knox (2007) has noted that online news sites are becoming increasingly similar in their visual-verbal structures, adopting conventions that result in an increased 'atomization' of news texts and decontextualization of the images that accompany them. Similarly, Frosh (2001: 626) points to a 'systematic industrialization' of visual culture brought about by the internet. Most images appearing in news texts today, he observes, are 'stock images that are not designed for specific texts' but rather for commercial purposes. Related to the commercialization of digital images is their searchability, the fact that news outlets seeking a suitable image for a story can find it by typing descriptors into search engines that are then matched with metadata attached to the images. Such changes, Frosh (2001: 267) argues, have led to a 'standardization and systematization of photographic practices on quasi-industrial lines and an abstraction of photographic images as exchangeable signs and cultural commodities' (267).

Approaching the issue of stock photography from a more social semiotic perspective, based on Kress and van Leeuwen's ground-breaking application of principles of systemic- 
functional linguistics to the analysis of images, Machin and Van Leeuwen's (2007) observe how stock photographs in corporate image banks such as Getty Images take on strikingly standardised meanings across different contexts, with certain kinds of images coming to serve as widely recognised symbols of things like 'success', and 'freedom' (Machin and van Leeuwen, 2007). At the same time, however, such images also depend on a certain amount of semantic ambiguity (Frosh 2001; Ward, 2007), which enables them to be appropriated into multiple different contexts. The way stock images simultaneously produce both fixity and flexibility in meaning potential, they argue, has enabled image banks, to act as mediators between local and global cultures and, in so doing, become 'a leading force in building the world's visual language' (Machin, 2004: 334), a 'language' that is 'demonstrably more homogenized, generic and limited in its iconography.'

Both Machin and van Leeuwen (2007) and Frosh (2001) point out a number of key features of stock images that contribute their promotion of visual stereotypes by simultaneously creating a stable visual lexicon (Barthes, 1977: 22), and creating ambiguity sufficient to facilitate their recontextualization. First is the use of 'generic' content and styles, including models whose appearance, clothing and behaviours are neither striking nor unusual (Frosh, 2002: 175; Machin \& van Leeuwen, 2007: 155). Of course, what is regarded as generic tends to reproduce the cultural values and conditions of the image producers. Second is a frequent backgrounding of the physical contexts in which the models are photographed by placing them in neutral, nondescript environments or by blurring the surroundings. Finally, there is the highlighting of attributes that index social identities and social practices - such as hard hats, white coats, and headscarves, thereby 'reducing the individual to the general, and the concrete to its essential qualities' (Kress and van Leeuwen, 2007: 170 see also Frosh, 2001; Ward, 2007).

Thurlow and his colleagues (2020) offer a slightly different perspective on the ideological dimensions of stock photography, focusing on the metadiscursive framing of 
images. In their exploration of the dominant conventions in stock images that visually represent young people and their digital practices they draw on Irvine and Gal's (2000) work on language ideologies, pointing out that processes of 'iconization', 'erasure' and 'recursivity' are also evident in the 'language' of stock photography, resulting in 'reductionistic' representations which, in the case of their data, also promote class and gender stereotypes.

When it comes to politics, the 'homogenization' and 'standardization' associated with stock images, however, does not necessarily result in ideological homogenization or the erasure of alternate perspectives. Aiello and Woodhouse (2016), for instance, have pointed out how platforms such as Getty Images have made an effort to promote more diverse and inclusive representations. Getty's Genderblend trend, for example, is framed by the company as a socially conscious attempt to portray gender as 'a nuanced spectrum' and to challenge 'previously fixed ideas of what it is to be male and female' (Grossman nd). Despite this ostensible attempt to challenge stereotypes, Aiello and Woordhouse point out that the processes of 'typing' these image employ, which highlight bodily attributes decontextualized from the social world, are not that different from those used in more conventional representations, and that processes of 'juxtaposition' used to highlight deviations from the norm can sometimes work to reinforce visual clichés. Rather than challenging stereotypes, then, attempts to produce more 'alternative' or 'authentic' stock images end up 'reinscribing ... “trailblazing” imagery into easily grasped clichés' in order to serve the agenda of consumer capitalism.

Few scholars have looked explicitly at how stock images are circulated and appropriated by different kinds of content producers into different contexts. One study by Aiello and her colleagues (2016) used Google Reverse Image Scraper to explore how images in Getty's 'Lean-In' collection (made up of images of 'empowered women) circulated online and the kinds of sites they were recontextualized into. They found that although images from this collection appeared on multiple kinds of websites (blogs, news websites, social media), 
fewer than a third of the images in the collection were found by the image scraper, with the same images tending to be used on multiple websites. They also found that images with different metadata 'tags' tended to appear on different kinds of websites, with, for example, tags for ethnicity popular on business related sites, and tags related to children and childhood popular on blog sites.

This study builds on many of the insights from the scholars cited above, combining a focus on how stereotypes are reinforced within the visual regimes of stock images with attention to how such images are made available to users through search engines and how they are adapted to different rhetorical and cultural contexts (for example, news sites and advertisements in different countries). Particularly of issue is the degree to which the ideological effects of such images are a result not just of the ways the images themselves are composed, but also of the affordances and constraints of the technical and metatextual means through which they are circulated and the social and professional practices these means give rise to and support, particularly the professional practices of journalists and those in the field of advertising. In such fields, images are increasingly chosen for news stories not just based on how well they represent or compliment the accompanying text, but also based on financial, technical and design considerations. Stock images often present the most convenient and economical solution for addressing these issues, allowing media producers to quickly search through image banks based on a range of criteria, avoiding the expense of having to produce images themselves. These images then become available to the general public through image searches based on the textual content accompanying their use. In this way, image banks, media producers, developers of search engines (and their algorithms), and internet users themselves all play a part in determining how stock images and the stereotypes they reproduce are circulated. 
The searchability of digital images is governed by two key techno-discursive processes: the association of metadata, in the form of semantic 'tags' with different pieces of content, and the use of algorithms to dynamically organize search parameters around references and crossreferences based on the way existing content is organized and on the past behaviour of users interacting with this content (Jones, 2021). Both of these processes work to construct ontologies of people and practices that come to dictate promote certain 'version of reality'. These processes have important consequences for understanding the role of images in the promotion of cultural stereotypes, since the 'meaning potential' of digital images is not determined solely by the 'indexical singularity' (Frosh 2002: 638) of shared cultural assumptions, but also by 'algorithmic logics' which are able to detect associations between seemingly disparate content and amplify stereotypical assumptions of users based on how they search for and use that content (Jones, 2020). Kay, Matuszek and Munson (2015), for example, have noted how gender bias and stereotypes tend to be exaggerated in image searches, and that exaggerated search results also have the power to shift people's perceptions about real-world distributions, affecting or reinforcing their biases. The tendency of search algorithms to amplify social biases has been noted by a range of scholars (Introna and Nissenbaum,2000; Pariser. 2011).

Our focus in this paper, then, is to explore the way the lifting of the ban on Saudi women driving was represented in international banks of stock images in 2018, the way some of these images were further circulated, becoming prominent results in Google Image searches, and finally, how selected images were actually used in the context of news stories and advertisements.

The data for the study is limited to the images that were available in the period immediately after the lifting of the ban when so many news outlets were searching for images to accompany stories about the policy changes and the events surrounding it. Since that time, of course, many 
more images have been produced and circulated, and an interesting focus of future research would be how these images might (or might not) have changed in the subsequent months.

The study was guided by the following questions:

1. How did images that circulated over the internet of Saudi women driving immediately after the lifting of the ban reinforce or challenge stereotypes around gender and culture?

2. How were these stereotypes constructed or challenged through the ways these images represented personhood and agency and the interpersonal relationships they established with viewers?

3. How did the meaning and function of such images change as they are embedded into different textual and cultural contexts?

4. How might the affordances of digital media (such as metadata attached to the images or the way they were made prominent by search engines) have affected the kinds of images that circulated, how they were used, and how they came to reinforce certain ontologies of Saudi womanhood?

\section{Methodology}

142 images and 4477 metadata tags were collected from Shutterstock, Getty Images and Goggle Images from 2 August to 28, August, 2018 using the search term 'Saudi women driving'. The rationale for choosing these sources of data involved their prominence. Shutterstock is the number one image bank in the world, and Getty Images was one of the first image banks to go online (currently $8^{\text {th }}$ in market share) (Datanyze, 2020). Google, of course, dominates the search engine market, with over $90 \%$ of worldwide market share (Oberlo 2019). Of course, there are other image banks, including regional image banks such as Gulf Images and FotoArabia +. Our focus, however, was on images that were available to a more global audience. Interestingly, even search results from Google Images conducted in 
Saudi Arabia tended to feature images from these international sources rather than regional ones.

Searches in image banks such as Getty Images and Shutterstock are based on metadata assigned to the pictures by these companies based on a particular taxonomy of conceptual terms, and so collecting these metatdata along with the images is useful both for understanding the kinds of ontologies around Saudi womanhood promoted by the companies, and the kinds of terms users would have had to type in to access particular kinds of images. Other factors governing search results in these image banks are recency and popularity. In Shutterstock, customers can filter search results to order the images returned based on the categories 'Most Relevant' and 'Fresh Content'. The default choice -'Most Relevant'1_-was used for our search. Getty Images similarly allows users to sort result based on the categories “Most Popular', 'Newest', 'Best Match'. In this case the default choice 'Most Popular' was used. The searches of Getty Images and Shutterstock took place on August 27, 2018. In the case of Shutterstock, the first 50 images returned were collected. In the case of Getty Images, only 42 images were retuned, and they were all collected for analysis.

Google images is a content-based retrieval system (Datta, Joshi and Li \& Wang 2008) which searches for images based not just on metadata associated with the images but also on the textual content of the pages in which they appear. The prominence of images in searchers is influenced by Googles PageRank algorithm (Google, n.d.), which considers how many 'hits' and links the pages on which these images appear have, as well as other factors such as recency and the geographical location of searchers. Based on these factors, the images retrieved from Google Image searches reflect the degree to which particular images are circulated and accessed and the popularity of the pages that they appear on. The search of Google Images was

\footnotetext{
1 'Relevance' in Shutterstock is based on an machine learning algorithm which, according to the company, over time, 'rewards images with accurate keywords' (though the exact formulae for this algorithm is not available to the public). See https://www.shutterstock.com/blog/shutterstock-new-search-order
} 
done by one of the authors based in Saudi Arabia. To control for possible effects of Google's personalization algorithm which sometimes delivers different search results to different users, an identical search was conducted by four other users based in Saudi Arabia, the US, the UK and Turkey. The results of these searches by different users were largely identical, although the order of the pictures returned varied slightly. The first 50 images returned were selected for analysis.

In the results of the Google search $64 \%$ of the images were from Western (US, UK, European and Australian) websites, mostly large news outlets such as $\mathrm{BBC}, \mathrm{CNN}$, Fortune Magazine and Time. Only 16\% appeared on Arab webpages, the rest appearing on Asian and African websites. In other words, most of the images returned from searches conducted in Saudi Arabia were not from Arab sources. ${ }^{2}$ Of these images over a quarter were attributed to image banks such as Google or Shutterstock. Around half were attributed to news services such as AP and Reuters, and the remaining images had no attribution (though most of them resembled photos available on image banks. In three quarters of the uses, the figure in the images was not named either in the caption or the story. Unsurprisingly, this was true for $100 \%$ of the images attributed to image banks.

The images and the metadata associated with those taken from image banks were imported into the qualitative analysis software Max QDA (VERBI Software, 2019) and analysed based on codes generated from the analytical framework described below. 15 images were chosen for closer analysis on the basis that they appeared in multiple contexts (such as news stories and advertisements). This analysis focused on how images from image banks were recontextualized to serve different communicative purposes.

\footnotetext{
${ }^{2}$ Google (known in Saudi Arabia as 'Uncle Google') occupies 98.25\% of the market in search. There are no native Arab search engines of any note in use in the country.
} 
The coding of the images was based on principles of multimodal representation laid out van Leeuwen (2008), as described below. At the same time, the analysis was informed by Goffman's (1987) work on representation as social ritual. In his analysis of representations of gender in advertisements, Goffman argues that commercial images often constitute a type of 'social portraiture' in which figures are arranged 'microecologically to depict what is taken as their place in the wider social frame' (6). Norms of interaction and aspects of social identity are communicated through such features as the actions that depicted figures perform, the physical positions they take up in relation to others, and their gestures, facial expressions, and clothing. Interestingly, Goffman makes a point about advertising images that is similar to that made by Frosh (2002) and Machin and van Leeuwen (2007) about stock images -- that the generic styling and arrangement of figures creates 'elaborations of human action that can be displayed across many social settings, in each case drawing on local resources to tell stories of very wide appeal' (6).

In his more social semiotic approach to the analysis of images, van Leeuwen (2008) advances a model of representation which in many ways echoes Goffman's notion of social portraiture, seeing discursive representations as a form of 'recontextualized social practice.' Van Leeuwen's model, like Goffman's, also takes into account both the ways figures within the images interact with one another, displaying identity related attributes and behaviours, and the way they interact with viewers of the images. The model focuses on a number of key dimension, including what sorts of figures are 'included' and 'excluded', the different 'roles' they play, whether or not they are depicted as 'specific' or 'generic', as 'individual' or in 'groups', and the attributes they have that allow them to be 'categorized' into different social groups. Exclusion indicates the choice of not including particular people or kinds of people, which may reflect practices of 'social exclusion' within the societies in which representations appear (142). Roles in visual representation refers chiefly to the roles people take visa vie some 
action or process as either 'agents', i.e. performing the action, or 'patients', i.e. receiving the action. People in images can also be visually represented as specific or generic, that is, either their status as unique individuals or representative 'types' of people can be highlighted, and they can also be represented singly or as members of groups. When they are depicted in groups, they can be depicted as similar to other group members (homogenization) or as different (differentiation).

The dimension of representation van Leeuwen discusses that is most relevant to our analysis is that of categorization (or stereotyping). Social categories can be visually signalled by means of various 'cultural' or 'biological' characteristics. Biological characteristics include things like sex, race/ethnicity, height, and body shape. Cultural categorization, as van Leeuwen (2008: 145-6) explains is 'signified by means of ... attributes commonly used to categorize these groups such as hairdo, headscarf and hijabs which ... connote the positive or negative connotations attached to that group by the group for whom the representations were produced.'

The second aspect of visual representation that van Leeuwen's model accounts for is related to how the represented actors in the images interact with viewers. Such interaction is normally accomplished either through technical aspects of photography (such as camera angles and framing) or through the actions of the depicted figure (such as whether or not she looks at the camera and the kind of facial expression she wears). This aspect is divided into three dimensions: Distance (reflected in the choice of close, medium or long shots), the kind of relations depicted between the actor/s in the image and the viewer (indicated by camera angle - whether it is frontal, high, eye level, or low), and the way the depicted figure interacts with the viewer (indicated by looking at the viewer or not.

Finally, our analysis draws on principles from mediated discourse analysis (Norris \& Jones, 2005; Scollon, 2001) focusing on how various mediational means: software interfaces algorithms, and metadata -- influence what kinds of images are available to different kinds of 
viewers and, the contexts in which they appear. In this regard, the inclusion of data from both image banks and from Google images allows us to consider not just what kinds of representations of Saudi women driving are available commercially, but how certain kinds of representations are amplified by Google's search engine, which makes images that have been used more frequently as well that those that have been used on more popular websites (such as those of national newspapers or popular magazines) more prominent. The addition of the Google images search, in other words, provides a perspective on how images on particular topics circulate and are taken up. Finally, closer analysis of actual webpages on which these images appear sheds light on how the 'generic' is rendered more 'specific' through the framing and anchoring (Barthes, 1977) actions of the accompanying text as well as the wider social, cultural or political contexts of which these websites are part.

\section{Multimodal Representation}

\section{Categorization}

The coding of the visual data aimed to reveal how social actors in the images were represented and the kind of relationships that were established between these social actors and viewers. Table 1 summarizes the number of figures appearing in each image, and the kinds of attributes the figures exhibited.

Table 1 Summary of social actor representation

\begin{tabular}{|c|c|c|c|c|c|}
\hline \multicolumn{2}{|c|}{ Social actor representation } & \multirow{2}{*}{$\begin{array}{l}\begin{array}{l}\text { Google } \\
\text { (n=50) }\end{array} \\
42(84 \%)\end{array}$} & \multirow{2}{*}{$\begin{array}{l}\text { Getty } \\
(n=42) \\
41(97.6 \%)\end{array}$} & \multirow{2}{*}{\begin{tabular}{|l|} 
Shutterstock \\
$(n=50)$ \\
$32(64 \%)$ \\
\end{tabular}} & \multirow{2}{*}{\begin{tabular}{|l|} 
Total \\
$(\mathrm{n}=142)$ \\
115 \\
$(80.9 \%)$
\end{tabular}} \\
\hline \multirow{4}{*}{$\begin{array}{l}\text { Number of } \\
\text { human } \\
\text { figures }\end{array}$} & 1 & & & & \\
\hline & 2 & $6(12 \%)$ & $1(2.4 \%)$ & $3(6 \%)$ & $\begin{array}{l}10 \\
(7.04 \%)\end{array}$ \\
\hline & 3 or more & $2(4 \%)$ & 0 & 0 & $2(1.4 \%)$ \\
\hline & Body Part Only & 0 & 0 & $15(30 \%)$ & $\begin{array}{l}15 \\
(10.5 \%)\end{array}$ \\
\hline Images & Female(s) & 50 & $42(100 \%)$ & $50 \quad(100 \%)$ & 142 \\
\hline
\end{tabular}




\begin{tabular}{|c|c|c|c|c|c|}
\hline \multirow{2}{*}{$\begin{array}{l}\text { containing } \\
\text { figures or } \\
\text { body parts } \\
\text { with female } \\
\text { and/or male } \\
\text { traits }\end{array}$} & & $(100 \%)$ & & & $(100 \%)$ \\
\hline & Male & $3 \quad(6 \%)$ & $1(2 \%)$ & $\begin{array}{l}2 \text { (children) } \\
(4 \%)\end{array}$ & $6(3 \%)$ \\
\hline \multirow{9}{*}{$\begin{array}{l}\text { Cultural } \\
\text { categorization } \\
\text { (Clothing } \\
\text { worn in } \\
\text { images) }\end{array}$} & $\begin{array}{l}\text { Clothing not } \\
\text { visible/recognizable }\end{array}$ & \multirow[t]{2}{*}{0} & \multirow[t]{2}{*}{0} & \multirow[t]{2}{*}{$15(30 \%)$} & \multirow[t]{2}{*}{$\begin{array}{l}15 \\
(10.5 \%)\end{array}$} \\
\hline & $\begin{array}{l}\text { (e.g. images of just } \\
\text { body parts) }\end{array}$ & & & & \\
\hline & $\begin{array}{l}\text { Traditional Islamic } \\
\text { clothing of any kind }\end{array}$ & $50(100 \%)$ & $42(100 \%)$ & $35(70 \%)$ & $\begin{array}{l}127 \\
(89.5 \%)\end{array}$ \\
\hline & Black abaya & $36(72 \%)$ & $39(92 \%)$ & $31(62 \%)$ & $106(74 \%)$ \\
\hline & Other colour abaya & $14(28 \%)$ & $3(7 \%)$ & $4(8 \%)$ & $21(14 \%)$ \\
\hline & $\begin{array}{l}\text { Head covering of } \\
\text { any kind }\end{array}$ & $50(100 \%)$ & $42(100 \%)$ & $35(70 \%)$ & 127 (89\%) \\
\hline & Hair covered only & $40(80 \%)$ & $19(45 \%)$ & $20(40 \%)$ & $79(55 \%)$ \\
\hline & (hijab) & & & & \\
\hline & $\begin{array}{l}\text { Hair and face } \\
\text { covered (niqab) }\end{array}$ & $10(20 \%)$ & $23(54 \%)$ & $15(30 \%)$ & $48(33 \%)$ \\
\hline
\end{tabular}

Not surprisingly, all of the images returned in our searches for 'Saudi Women Driving' include women along with objects associated with the action of driving. What tends to be excluded in these images are men and children: men appeared only in 4 images, and children, in only 2. In all of these cases, however, the men and children appear to have been included mainly to emphasize the roles of the women pictured as wives and/or mothers. Two of the images depict two women. In all of the rest of the images, the women appear singly. The Google search retuned slightly more images of accompanied women then appeared in the Getty image search. Interestingly, almost a third of the images in the Shutterstock corpus depicted 
only body parts of women --for example, a hand grasping a steering wheel-- yet none of these images appeared in the top 50 results returned by Google Images.

The figures in the images from image banks appear mostly to be models, based on the fact that, in the image banks they often appear in multiple images striking various poses, and when they are used on webpages the identity of the figure is not included. These 'generic models' (Machin and van Leeuwen, 2007: 152) are all conventionally attractive and lack particularly striking physical characteristics. While about a third of the images retuned by the Google search contain named figures, none of them are recognisable public figures such as politicians, legislators, government officials or activists who played a role in the lifting of the driving ban. Rather they are meant to represent 'typical' Saudi women, and the captions that accompany such images usually say something like:

Razan, right, sits for the first time in the driver's seat, with her trainer.

Daniah al-Ghalbi, a newly-licensed Saudi woman driver, during a test-drive in the Red Sea resort of Jeddah.

These 'typical' female drivers are all posed in the same way as models in the image banks photos, offering an uncomplicatedly positive depiction of Saudi women driving. The lack of identifiable individuals in both the image bank data and the Google search demonstrates how conventions of stock images meant to depict generic figures can affect even genuine photojournalism, crowding out images of actual newsmakers and facilitating the depoliticization of the reporting of events.

As anticipated in van Leeuwen's visual social actor network discussed above, the 'generic' identities of these figures are communicated through biological and cultural categorization. Table 1 summarizes the traits associated with this categorization.

The most salient biological characteristic, of course, is sex. Even in images that just include body parts, the gender of the figure is clearly signalled though characteristics that traditionally 
index femininity (long nails, nail polish, jewellery). Another important set of biological characteristics are those indexing race or ethnicity. The models in all of the images (in which the model's face is visible) have biological features associated with Arabs (dark hair, brown eyes, and medium light skin). Notably, although there are a variety of ethnic groups and a range of skin pigmentations represented, none of the figures are of dark-skinned Arabs or ethnic minorities (e.g. Afro-Asians).

Cultural categorization is primarily communicated through dress. Features of Islamic female dress are present in all of the Google, and Getty images, and in 100\% of the Shutterstock images in which the clothing of the figures is discernible. As shown in Table 1 above, the abaya and some kind of head covering (either hijab or niqab) is found in all images in which the clothing of the figures is visible. Interestingly, in our data, the image banks contain a greater number of images depicting more traditional head covering in which both the hair and the face is covered (see Figure 1) (54\% in Getty Images and 30\% in Shutterstock), whereas only $20 \%$ of images returned in the Google search featured this kind of head covering, with the less conservative hijab (covering only the hair) (see Figure 2) much more prominent.

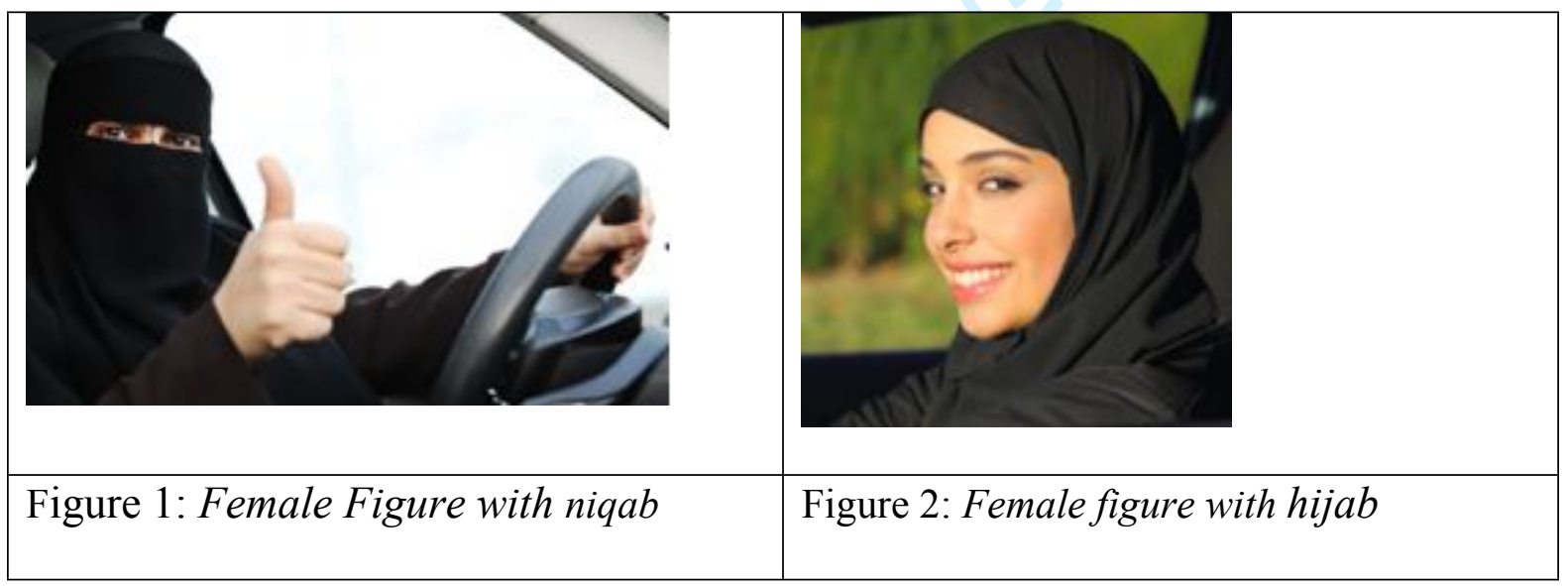

Despite the biological and cultural markers intended to signal 'Saudiness', the question remains whether or not the models in the images appear Saudi to actual Saudi viewers; some 
of the models have ethic characteristics not typical of Saudi women or wear their head covering in a style not typical of Saudis. To test this, representative pictures of the 5 models in the Getty image data were shown to 497 Saudi respondents via an online questionnaire (See Figure 3 below):

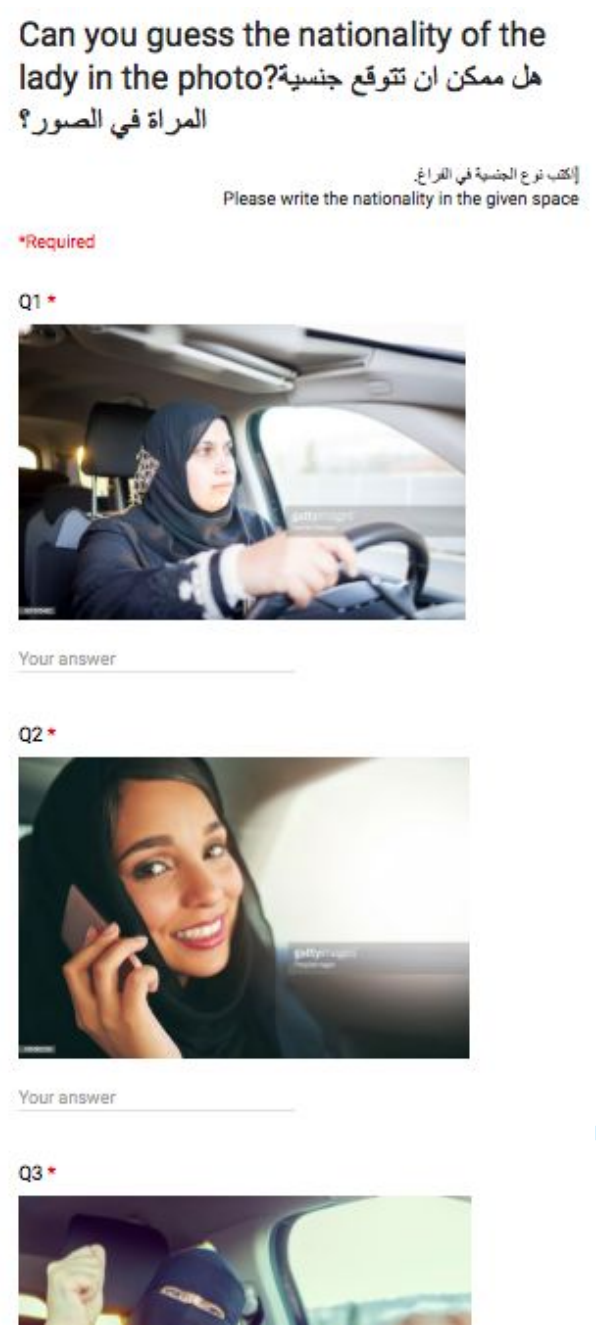

Figure 3. Guess the nationality questionnaire

As can be seen in table 2, none of the models were identified as Saudi by a majority of respondents, and two of them, model 1 and model 5 were overwhelmingly deemed not to resemble Saudi women. Respondents assigned a range of other nationalities to models such as Egyptian, Syrian, Kuwaiti, Pakistani and Jordanian. 
Table 2 'Guess of models' nationality' survey results

\begin{tabular}{|l|l|l|}
\hline $\begin{array}{l}\text { 'Can you guess the nationality of the lady in the } \\
\text { photo?' }\end{array}$ & Saudi & $\begin{array}{l}\text { Non-Saudi } \\
\text { Iraqi) (Egyptian, Syrian, }\end{array}$ \\
\hline Model 1 & $6(1.5 \%)$ & $\begin{array}{l}\text { Ki.5\% (Bahraini, Emarati, } \\
\text { Kwaiti, Morrocan) }\end{array}$ \\
\hline Model 2 & $107(20.5 \%)$ & \\
\hline
\end{tabular}

Figure 4: Online survey

Although it is difficult to say why respondents made these judgements, the most important thing to note is that the generic features of ethnicity and dress which are intended to communicate 'Saudiness' do not necessarily communicate this to actual Saudis. Rather, what seems to be depicted are 'generic Arabs' with little or no sensitivity to the sometimes-subtle differences in facial features and clothing style that may distinguish different kinds of Arab women from one another. In other words, these images show a kind of erasure of subtle regional/national differences in ethnicity and dress, lumping all Islamic and/or Arab women into one category. Interestingly, the figures who were considered 'Saudi-looking' by most 
respondents were those wearing niqab (models 3 and 4), while the Google search suggests that journalists and content designers looking for images of Saudi women driving were less likely to choose figures dressed in this way, even when they were amply represented in the image banks (see above), perhaps because they contradicted the preconceived notions of more 'emancipated' Saudi women that they brought to their choices.

\section{Agency/Transitivity}

The degree of agency assigned to figures in images, communicated though pictorial resources that signal transitivity (Kress and van Leeuwen, 2006), is an important issue when analysing depictions of Arab women. As noted above, for example, Al-Malki et al. (2012), found that women in Arab media were generally portrayed in more agentive positions than were Arab women in Western media.

Kress and van Leeuwen divide images into two types based on the kinds of processes they depict. What they call narrative images depict material or action processes, whereas analytic images depict relational or behavioural processes. Obviously, however, many images depict a combination of processes. For example, an image may depict a woman grasping the steering wheel of a car (a material process), sitting next to a driving instructor (a relational process) and smiling (a behavioural process). In our corpus, $88 \%$ of the images count as narrative images, that is, they depict a woman performing some kind of material process vis$\grave{a}$-vis an object (such as pressing an ignition button, applying lipstick, getting into a car). Most of these actions, however, are rather mundane, and some are only peripherally related to the action of driving (see below). None of the images depict the woman visibly interacting with another human. $11.9 \%$ of the images depict relational processes, for example, a woman standing next to a car but not performing any visible material action. In addition to material and relational processes found in the collected data, there are also behavioural processes. Behavioural processes refer to "physiological and psychological behaviour, like breathing, 
dreaming, smiling, coughing." (Halliday, 1985: 128). 42\% of the images depict agents performing clear behavioural processes such as smiling and gesturing 'thumbs up'. Such processes might also constitute types of 'non-verbal verbal' processes when perceived as being directed towards the viewer with a communicative intention (see Table 3 below).

Table 3: Types of processes

\begin{tabular}{|l|l|l|l|l|}
\hline \multirow{2}{*}{ Type of Process } & \multicolumn{3}{|c|}{ Number of images } & \multirow{2}{*}{$\begin{array}{c}\text { Total } \\
(\mathrm{n}=142)\end{array}$} \\
\cline { 2 - 4 } & Google $(\mathrm{n}=50)$ & Getty $(\mathrm{n}=42)$ & $\begin{array}{l}\text { Shutterstock } \\
(\mathrm{n}=50)\end{array}$ & \\
\hline Material & $41(82 \%)$ & $39(92.8 \%)$ & $45(90 \%)$ & $125(88.02 \%)$ \\
\hline Relational & $9(8 \%)$ & $3(7.14 \%)$ & $5(10 \%)$ & $17(11.9 \%)$ \\
\hline Behavioural & $24(48 \%)$ & $18(42.8 \%)$ & $18(36 \%)$ & $60(42.2 \%)$ \\
\hline
\end{tabular}

All of the narrative images depict women in agentive positions, conforming to the idea of female 'empowerment' emphasized throughout the corpus. Interestingly, however, none of the pictures actually shows a woman driving, that is, the car in all instances is stationery which might be due to the technical constraints of producing highly quality photographs in a moving vehicle. Rather, the idea of driving is portrayed though other actions, mostly the action of holding a steering wheel, which is depicted in $52 \%$ of the images. In fact, apart from these 'performances' of diving, the women in the images engage in a rather narrow range of actions, and sometimes these non-driving related actions undercut the message of female empowerment (e.g. putting on lipstick with the aid of the rear-view mirror). The following is a list of all the material processes found in the data and the number of occurrences:

Table 4: Social actors representation as agents

\begin{tabular}{|l|l|l|l|l|}
\hline Type of action & Google & Getty $(42)$ & Shutterstock & Total \\
\hline Holding the steering wheel & $34(68 \%)$ & $16(38 \%)$ & $25(50 \%)$ & $75(52 \%)$ \\
\hline Pressing a button & $2(4 \%)$ & 0 & $6(12 \%)$ & $8(5 \%)$ \\
\hline Using a phone & 0 & $3(7 \%)$ & 0 & 3 \\
\hline Holding car keys & 0 & 0 & $2(4 \%)$ & 2 \\
\hline Applying lipstick & 0 & 0 & $1(2 \%)$ & 1 \\
\hline Looking over shoulder & $1(2 \%)$ & 0 & 0 & 1 \\
\hline Holding and looking at papers & $1(2 \%)$ & 0 & 0 & 1 \\
\hline Fastening seat belt & $1(2 \%)$ & 0 & 0 & 1 \\
\hline Getting into a car & 0 & 0 & $1(2 \%)$ & 1 \\
\hline Holding a sign & 0 & 0 & $1(2 \%)$ & 1 \\
\hline
\end{tabular}




\section{Relationship with viewers}

Apart from agency, the status of the women in the images is also affected by the kinds of relationships they establish with viewers. As explained above, van Leeuwen (2008: 141) operationalizes the relationship between viewers and the social actors depicted in images in terms of distance (close or far), relation (power and involvement) and interaction (direct or indirect address, usually indicated by gaze). Table 5 summarizes these dimensions:

Table 5: Representation of viewer relationship in Google, Getty and Shutterstock

\begin{tabular}{|l|l|l|l|l|l|}
\hline Representation of Relationship & Google & Getty $(42)$ & Shutterstock & Total \\
\hline \multirow{2}{*}{ Distance } & Close & $49(98 \%)$ & $42(100 \%)$ & $49(98 \%)$ & $140(98.5 \%)$ \\
\cline { 2 - 6 } & Far & $1(2 \%)$ & 0 & $1(2 \%)$ & $2(1.4 \%)$ \\
\hline \multirow{3}{*}{ Involvement } & Front view & $8(16 \%)$ & $24(57 \%)$ & $20(40 \%)$ & $52(37 \%)$ \\
\cline { 2 - 6 } & Side view & $42(84 \%)$ & $18(42 \%)$ & $30(60 \%)$ & $90(63 \%)$ \\
\cline { 2 - 6 } & From above - & 0 & 0 & $6(12 \%)$ & $6(4 \%)$ \\
\cline { 2 - 6 } & From below + & $9(18 \%)$ & $16(38 \%)$ & $6(12 \%)$ & $31(21 \%)$ \\
\cline { 2 - 6 } & Eye-level (equality & $41(82 \%)$ & $26(61 \%)$ & $38(76 \%)$ & $105(73 \%)$ \\
\hline \multirow{3}{*}{ Interaction } & Indirect address & $24(48 \%)$ & $25(59.6 \%)$ & $19(38 \%)$ & $68(47 \%)$ \\
\cline { 2 - 5 } & Direct address & $26(52 \%)$ & $17(40.4 \%)$ & $17(34 \%)$ & $60(42 \%)$ \\
\hline
\end{tabular}

As the table shows, the majority of images were taken at a close range and position the depicted actor and the viewer on an equal level. Images depict social actors from both front and side views, though the proportion of side-view images returned in the Google search exceeds considerably the proportion of side-view images available in the image banks. Kress and van Leeuwen (2006) argue that the difference between the oblique and the frontal angle is the difference between detachment and involvement, and so the prevalence of side-view images, even those in which the figure turns her head to gaze at the viewer, might create more of a sense of the woman as a spectacle. In other words, while images which created more involvement with the viewer through use of the frontal angle were amply available in both image banks, images that actually appeared on websites tended to be those which created a slightly more distant relationship between the viewer and the woman depicted. 
At the same time, slightly more than half of the pictures returned in the Google image search depict the social actor gazing at the viewer. Whereas the angle from which the figure is depicted has to do with involvement, gaze has to do with interaction. A figure in an image gazing at the viewer demands that the viewer establish some kind of relationship, the kind of relationship often clarified by the expression on the figure's face. In the case of these images, the figure gazing is almost always smiling, inviting a rather uncomplicated relationship of affinity or appreciation from the viewer, saying, in effect, 'I'm happy; be happy for me.'

Another aspect that is relevant to the establishment of relationships with viewers has to do with the modality of the images. Kress and van Leeuwen (2006: 154) define visual modality as a function of cues that signal whether viewers should regard what is depicted as "true, factual, real, or $[\ldots]$ a lie, a fiction, something outside reality." All of the images in the corpus depict social actors sharply, with high colour saturation, communicating 'realism'. In some of the images, however, the sharp focus of the social actor is set against an out of focus background. This strategy is typical of stock images, and, according to Machin and van Leeuwen (2007) helps give such images a 'timeless' and 'generic' quality. In most of the images, because of the focus on the figure and the blurring of the background, although the women are portrayed as 'performing' the act of driving, there is no sense of where they are or where they are going. According to Kress and van Leeuwen (1996: 165) 'by being decontextualized, shown in a void, represented participants become generic, a "typical example", rather than particular, and connected with a particular location and a specific moment in time'.

\section{Metadata}

What is important about stock images in digital environments is not just the representations themselves, but also how they are made searchable to those who might want to use them. Typically, searchability in such contexts is the result of metadata being appended to 
an image. Metadata can help to reveal constellations of concepts associated with Saudi women in the image banks, concepts which invariably reflect cultural (as well as commercial) assumption about things such as gender, ethnicity, and place, as well as more abstract concepts such as 'happiness'. This metadata also has an inevitable impact on how images are ultimately recontextualized into different discursive environments, since they govern the results journalists and other content creators get when they search for certain types of images.

The metadata associated with these images consists of both categorical terms, words associated with particular types of objects people or actions, such as 'Saudi', 'women' and 'driving', and conceptual terms, words associated with abstract ideas or emotions such as 'happiness', 'power' and 'independence'. Conceptual terms refer to broader evaluative and ideological frameworks through which the images are meant to be read.

To analyse the metadata attached to images, we categorized the words we found into eighteen semantic fields such as 'automobile- related', 'gender related' 'affect/emotion related' and 'education related'. Coding into semantic fields was done independently by each author and results were discussed and reconciled. Number of types, tokens of words from each semantic field were calculated. Figure 5 presents the number of tokens in each semantic field from the Shutterstock and Getty corpora. 


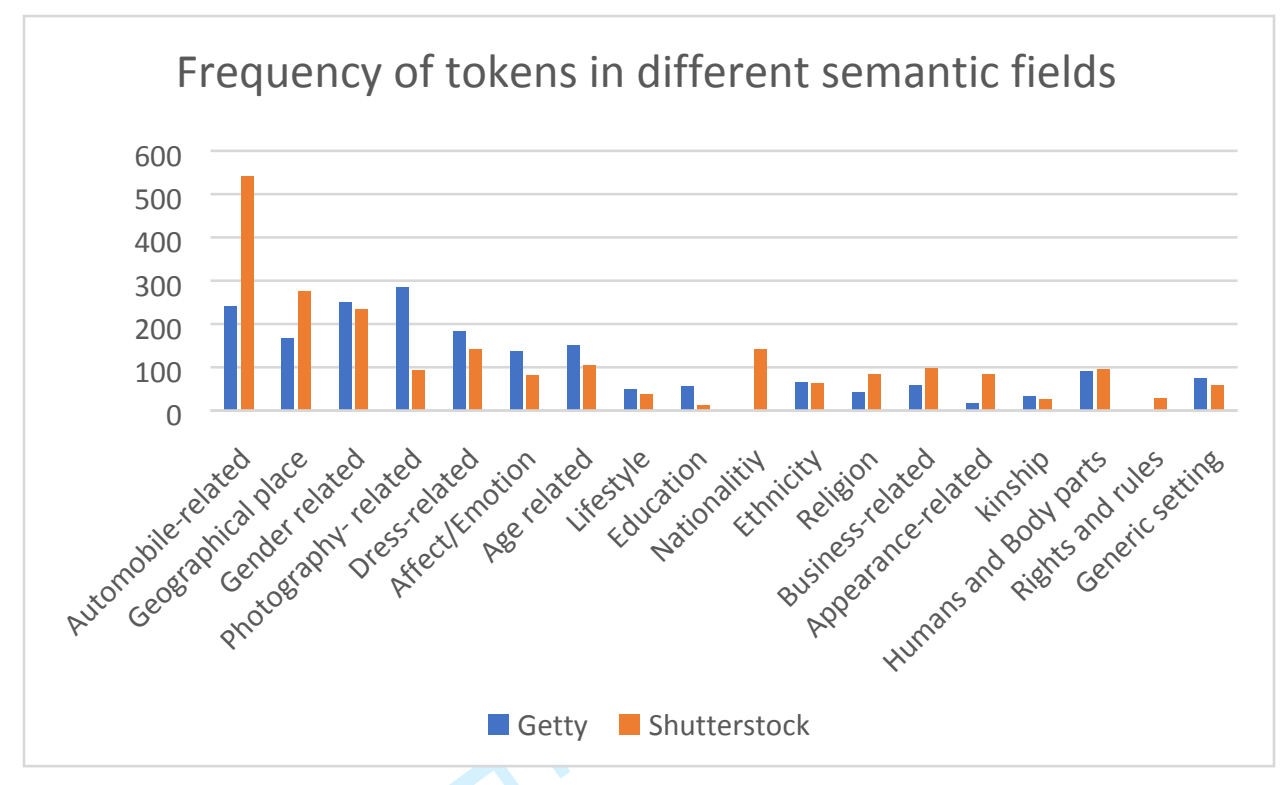

Figure 5. Frequency of tokens in different semantic fields

Our analysis of the semantic fields represented in the metadata reveals that words related to some fields are more frequent than others. It is not surprising that the three most dominant semantic fields represented in the metadata for images found with the search term 'Saudi women driving' are 'automobile-related' (e.g. car, vehicle, driver), words denoting geographical places (e.g. Saudi Arabia, Gulf Countries, Riyadh), and 'gender-related' words (e.g. woman, women, female). It is also not surprising that a large number of images taken from image banks are tagged with photography-related terms such as portrait, horizontal, inside, close-up, color image. What is more interesting is the frequency of other semantic fields having to do with dress, affect and age. 'Dress-related words' constitute the fifth most frequent semantic field in the metadata, and, importantly, all of the words used refer to items of clothing associated with Arab women such as (in order of frequency) scarf, hijab, niqab, religious dress, veil, modest clothing, and headscarf. 'Affect/emotion-related' words make up the sixth most frequent semantic field, and all of these denote positive emotions (e.g. happy, happiness, smiling, excited). Finally, the fifth most common semantic field is 'age-related' words such as adult, young adult, and young. There are no references to old age in the metadata, reflecting the fact that there are no elderly women depicted in any of the images. Other semantic fields 
represented in the data include words having to do with lifestyle (e.g. city life, modern, luxury, wealth), education (e.g. learning, student, learning to drive), religion (Islam, Muslim, Islamic) and appearance (e.g. beauty, beautiful, attractive pretty).

What an analysis of the metadata can add to our previous analysis of the images is both a clearer understanding of how social reality is construed in the images (and which aspects of that reality are made salient) and an understanding of the kinds of terms the owners of the image banks anticipate customers will use when searching- that is how they believe users themselves divide up and label things in the world. In this case, the ontology presented divides social actors along the lines of gender and nationality, and, more importantly, stereotypically construes dress as a salient marker of gender and nationality. It also, in this context, construes women in subordinate positions in terms of knowledge (with tags such as learner and learning to drive), and reinforces stereotypical associations between women and appearance (with tags such as beautiful and pretty). Finally, it presents an image of Saudi women driving that is almost universally associated with positive affect, physical attractiveness and/or a wealthy unban lifestyle. In this regard, the metadata analysis also highlights affective aspects of Saudi women driving that are not present in the images, such as, for example, concern, hesitancy or apprehension. What is presented is uncomplicated version of joyful, liberated 'Arabicity' that fits in with dominant Western interpretations of the new policy as well as the more general commercial tendency towards affect: the representation of 'happy people' (Thurlow, Aiello \& Portmann, 2020).

\section{Recontextualization}

This section examines how images of Saudi women available from image banks are appropriated into different contexts such as advertisements and news stories. This analysis was 
conducted by matching images from the Getty and Shutterstock corpora to images found via Google Images.

The following image (Figure 6) is a Shutterstock photo labelled with the metadata 'arab-woman-driving-car'. The Google image search for 'Saudi women driving' detected that this image had been used in at least three different contexts.

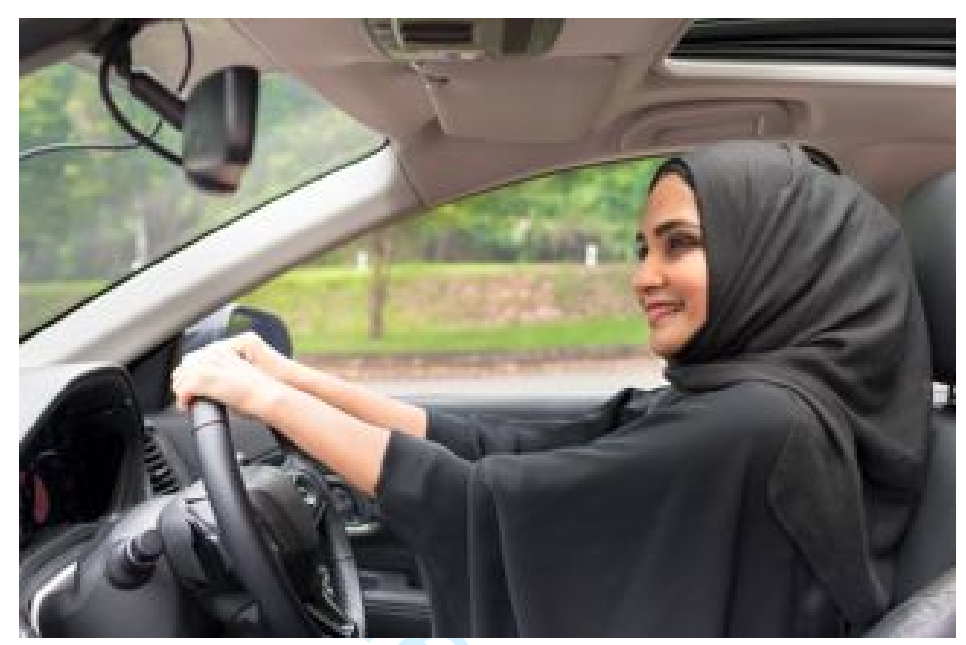

Figure 6. A photo from Shutterstock under 'arab-women-driving-car'

One was a story about events sponsored by municipal governments in Saudi Arabia to mark the lifting of the ban on women driving published in Al-Arabiya on June 21, 2018 three days before women were actually permitted to drive (Figure 7). In other words, rather than depicting an actual woman driving, this stock photo - along with the caption 'Women will be allowed to start driving in Saudi Arabia starting from June 24' -- was chosen to depict an idealized image of the future of Saudi women driving. The contents of the article are generally celebratory, commensurate with the positive affect displayed on the model's face. 


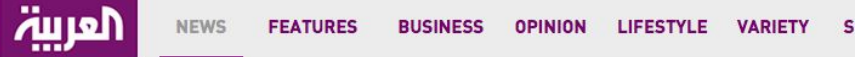

\section{Saudi cities launch community driving events for women}

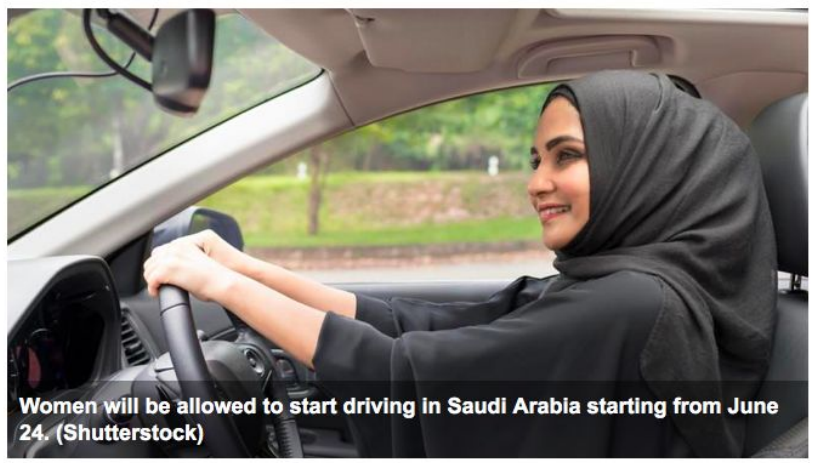

Staff writer, Al Arabiya English

Thursday, 21 June 2018

Text size $\underline{A} \underline{A} \mathbf{A}$

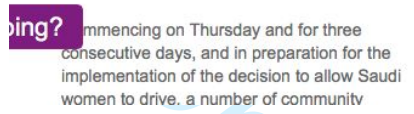

Ad closed by Google implementation of the decision to allow Saudi women to drive. a number of commun

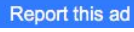

Figure 7. A Shutterstock image used in Al Arabiya news

Interestingly, this is not the first time this photo had been used by this news outlet.

On the previous day, June 20, 2018, it accompanied an article with the headline 'How Saudi Women driving has changed gender discourse in the West' and the caption ' Many Saudi women don't want to lose the guardianship rule because they feel safety being cared for' (Figure 8). Here, the image is recontextualized within events on a wider 'scale': rather than the local scale of municipal celebrations, it is meant to be interpreted on the scale of international relations and intercultural difference, On this scale the smile the woman's face takes on a very different meaning, becoming a challenge to Western discourses that portray Saudi women as oppressed. The caption re-orients the way viewers might interpret the smile, suggesting that it might partly be due to the fact that the figure can now drive, but to her feeling of 'being cared for' in the context of the guardianship system (under which Saudi women need the permission of a male guardian to leave their homes). 


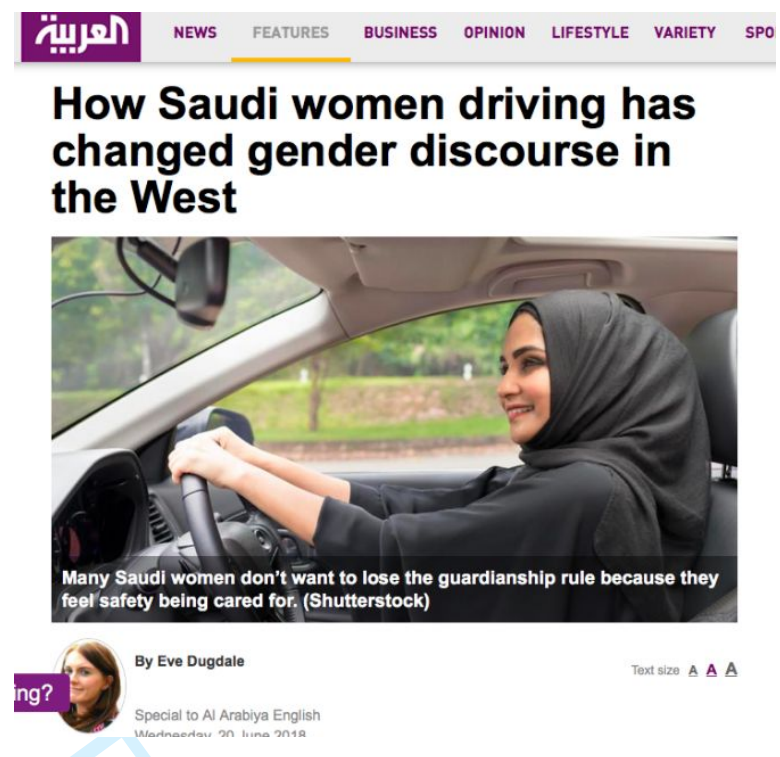

Figure 8. Different context, same photo

Another example of an image that shows up in different contexts is the Shutterstock image below (Figure 9). In the Google images search, this image was found on the website for the Montenegrin version of the international fashion magazine Cosmopolitan (Figure 10).

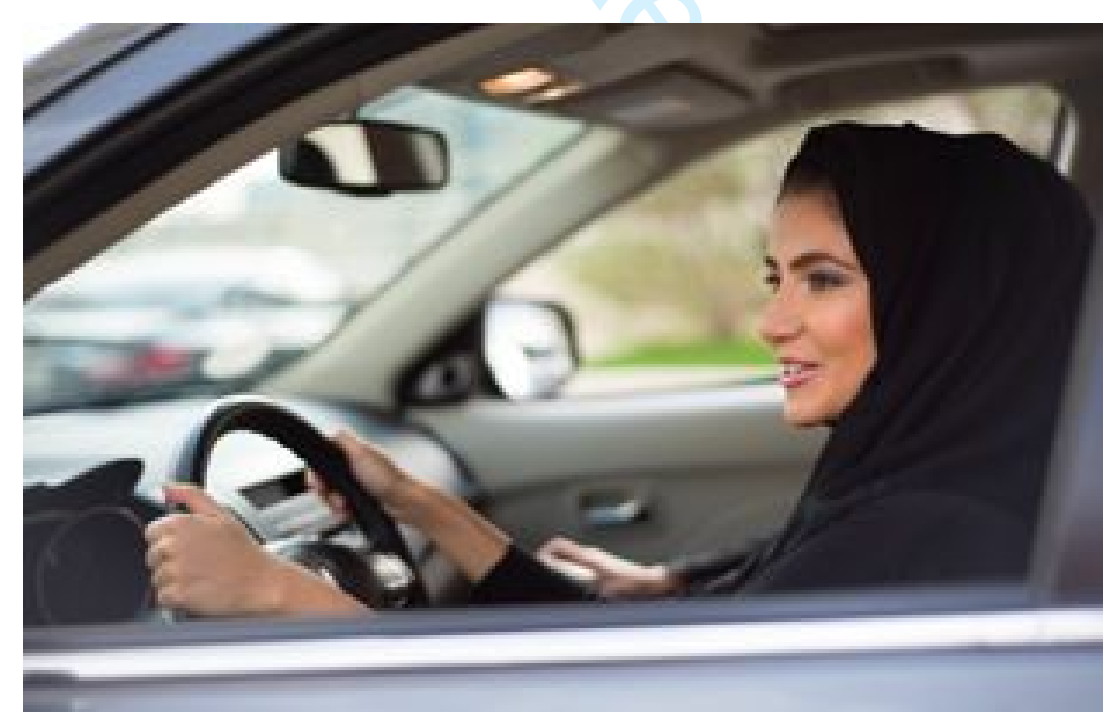

Figure 9. Shutterstock image 'Arab-woman-driving-car' 


\section{Saudi Lifts Ban On Female Drivers}

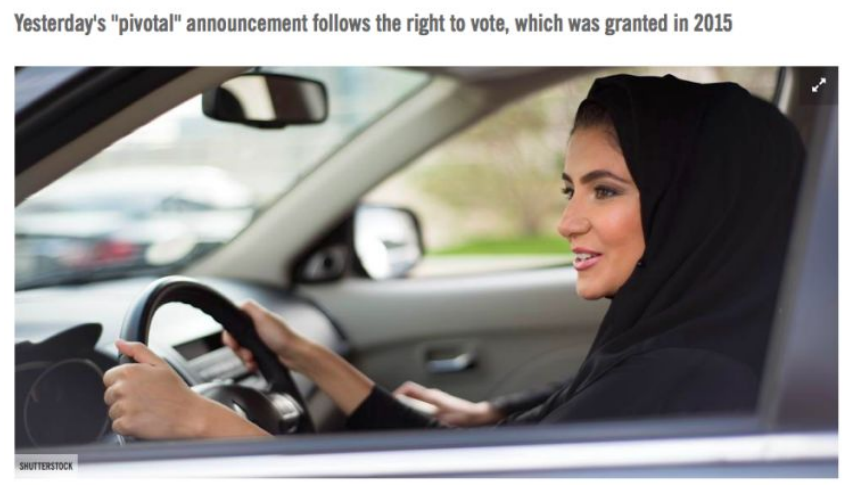

Figure 10. A Shutterstock image used by Cosmopolitan

https://www.cosmopolitanme.com/content/4883-saudi-lifts-ban-on-female-drivers

This article reports on an interview with Manal al-Sharif, a Saudi women's rights activist who was instrumental in starting the women's right to drive campaign in 2011 (and later faced arrest). The article is unreservedly celebratory in tone, including screenshots of the congratulatory tweets from a range of mostly Western celebrities such as Ivanka Trump and Kardashian mother Kris Jenner. What is interesting is that rather than including a picture of alSharif herself, the publication chose to use this stock image, eschewing the opportunity to particularize and politicize their depiction of the event.

The fashion magazine Marie Claire, used a photo of the same model, this one with the woman tilting her face slightly towards the camera (Figure 11), to express a similar celebratory attitude and also including screenshots of tweets. The headline, however - 'Saudi Women can *Finally* Drive Themselves Around'-imbues the article with a kind of 'snarky' edge which simultaneously celebrates the change and belittles it. 


\section{marieclaire}

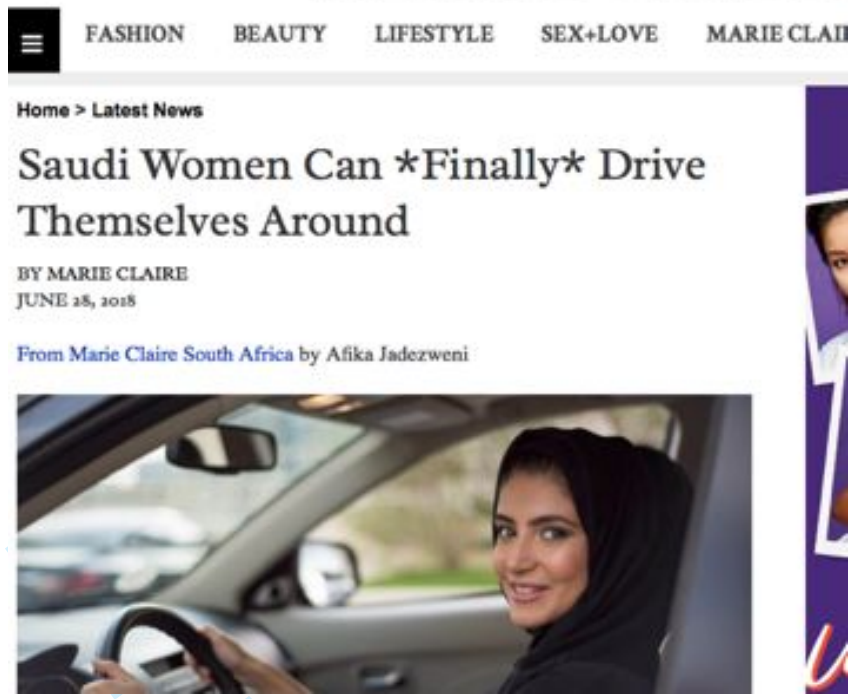

Figure 11. Saudi Women Can *Finally* Drive

https://marieclaire.com.my/latest-news/saudi-womens-travel-ban-lifted/

At the same time, this is not the only 'spin' that an image like this makes possible.

The same picture also appeared in a story on the website Asia Media International which comes with the more sceptical headline: 'Women driving in Saudi: Women's right's victory or economic ploy?' The article is sharply critical of the Saudi regime, and suggests that lifting the ban on women driving might have more to do with a desire to boost oil prices than to advance women's rights.

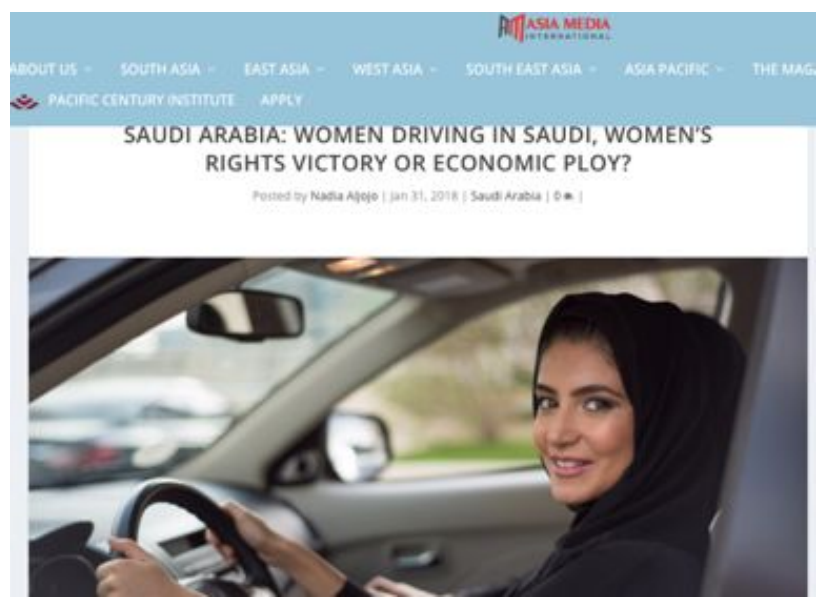

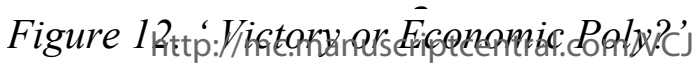


https://asiamedia.lmu.edu/2018/01/31/saudi-arabia-women-driving-in-saudi-womensrights-victory-or-economic-ploy/

Finally, the image also appears in an article from the Indian website The Indian Awaaz (Figure 13). This article, however, although it mentions the lifting of the ban on women driving, is not centrally about this topic, sporting the headline 'Saudi Arabia names first woman to senior government post'. One effect of the use of this picture is to suggest a relationship between this high-level appointment and the decree to end the ban on women drivers, though there no clear connection between these two events. Another possible effect is to suggest that the model pictured in the photo is actually the newly appointed assistant mayor of Al Khubar governorate, Eman Al-Ghamidi. She is not. Really what you have here is a kind of iconization of Saudi women diving to communicate the generic idea of the advancement of women's rights in Saudi Arabia and the Middle East more broadly.

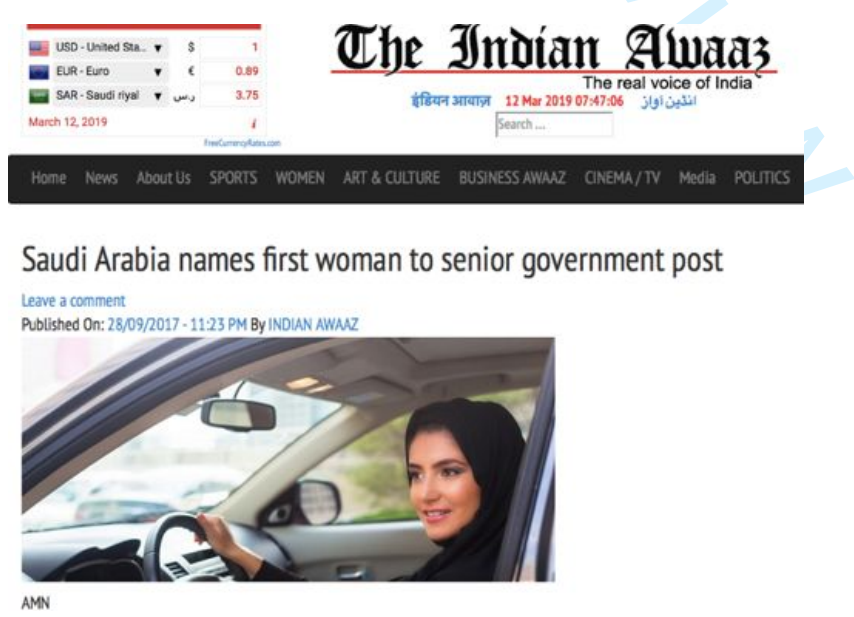

Figure 13. Saudi Arabia names first woman to senior government post

What is clear from this analysis is that in the context of news reporting stock images of Saudi women driving have been appropriated into a wide range of social, political and ideological contexts, the same image, for instance, being used to promote the official voice of 
the Saudi government, to champion global feminist discourses, and even to criticise Saudi leaders and cast doubt on their motivations for lifting the ban. The ideological 'flexibility' of these images is perhaps not surprising given their generic nature; none of the images we collected actually have any strong political or ideological message. What is perhaps more interesting is the way recontextualized images of Saudi women driving become unmoored from the concrete policy and the events surrounding it, becoming associated with other events, such as the promotion of a woman politician to a senior post, and with broader tropes about women's rights and cultural differences.

Another way stock images of Saudi women driving are recontextualized is in advertisements. Here, generic images of Saudi women driving are used for commercial purposes, to 'cash in' on this 'historical event' by associating with a particular product.

In Figure 14, a stock image from Shutterstock showing a woman in a niqab looking out of the windscreen of a car is used to advertise a restaurant offering free lunch to the first woman who drives herself to the restaurant. In this case, the advertiser benefits broth from the generic nature of the image, and from a particularization of the action portrayed by deploying it in the service of its own narrative - the woman pictured, it is suggested, is actually driving to the restaurant, whose name is superimposed onto the windscreen as if it were part of the environment. Other elements in the stock photo are also exploited; for example, the phone number and directions to the restaurant are printed just below the sat-nav screen in the car and a map to the restaurant is photoshopped onto the screen. 


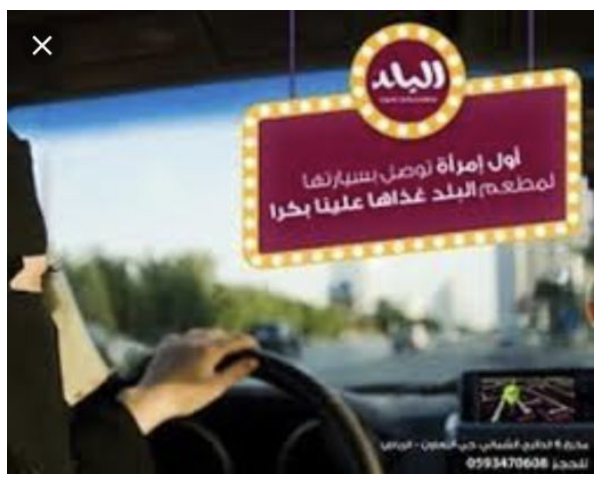

Figure 14. Free lunch

The same stock image was also used to advertise an auto repair company, which offered free services for the first 100 women who crashed their car. Here again, advertising elements are strategically superimposed on the image so that they interact with elements in the picture. The blue rectangle in which the offer is communicated, for instance, almost totally covers the windscreen, obscuring the diver's view (making a car crash more likely!). More importantly, the offer itself and the condescending way it is expressed reinforces stereotypes about women being poor drivers. Notably, the offer applies to the first 100 'girls' (بنت), as opposed to the word 'woman' (امراة) which was used in the previous advertisement, who have crashed their cars, the agency for the 'crashing' (تصدم) being attributed to the 'girls' (rather than saying something like 'girls who have been involved in an accident').

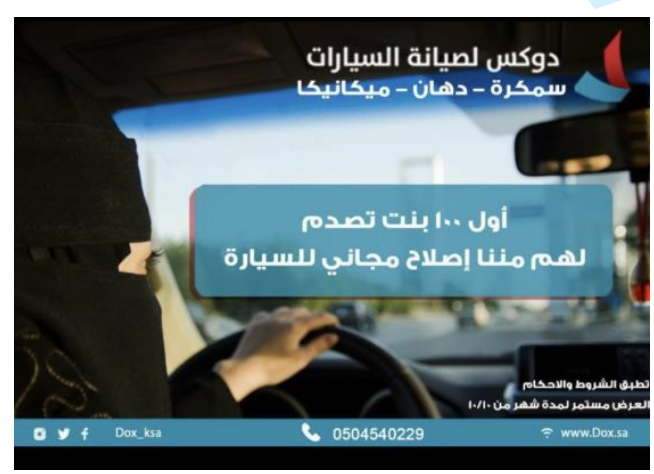

Figure 15. Free service for first 100 girls crashing 
Obviously, the aim of appropriating images into advertising is different from that of appropriating them into news reports, depending more on eliciting positive associations from viewers which can then be transferred to the advertised product. One way this is done is through creatively repurposing of the images in order to recruit the figures into the storylines of brand narratives. The generic women in the photos become characters in stories told by the advertisers. What is important to note is that many of these advertisements, while exploiting the trope of female empowerment that underlies these images, actually end up undermining this trope by promoting stereotypes of female helplessness or making light of the historical nature of the policy.

\section{Discussion and Conclusion}

Scholars such as Goffman (1987) and Machin and van Leeuwen (2007) have pointed out the role of images in print media in reproducing stereotypes, especially around gender. Goffman links the effects of images to the way they reinforce 'micro-ecological' norms governing social interaction. Machin and van Leeuwen expand this perspective to consider the economic forces of globalization and the ways gender ideologies travel across global and local contexts. What we have attempted to add to this discussion is a more focused discussion of the role of mediation in the reproduction of stereotypes, exploring how technological tools affect the ways images are circulated, recontextualized, and the kinds of representations that get seen or do not get seen.

Many of the observations made by Goffman, and Machin and van Leeuwen can also apply to the images that we have analysed. The figures in the images in our corpora are generic Arab women whose cultural identity is reduced to a few discrete characteristics (such as head scarves). The contexts of the images are more or less erased, and the mood they create is unproblematically positive. While most of the images depict the women in agentive positions, 
The reason for this is likely that the same commercial incentives that compel image banks to produce generic images that are able to be exported into multiple textual contexts also guide those who use these images, causing them to choose images that most efficiently index what they believe to be readers' stereotypes about the way Saudi women are supposed to look and how they are supposed to feel about *Finally* being able to drive. This narrowing of the range of ways particular kinds of people and particular kinds of ideas get represented based on these commercial incentives is further amplified by the speed and efficiency by which such images circulate online governed by the operations of algorithms. Google's algorithm, for instance, is designed to make images that appear on websites of larger international media 
outlets (such as Cosmopolitan and Marie Claire) more prominent. The consequence, at least in the case of Saudi women diving, is that more generic representations tend to crowd out specific representations of particular Saudi women driving in particular places for particular reasons, images which would help to open up space for a more nuanced and situated understandings of the situation of Saudi women.

Finally, as we have shown through our analysis of the metadata associated with these images in the image banks, the ways the images are made searchable can further reinforce stereotyped associated between Saudi women driving and certain conceptual categories, thus subjecting these representations to increasingly rigid ontologies having to do not just with social actors and the actions they are engaged in but also conceptual categories around topics like class, education and affect.

As a result, the world that people are exposed to (particularly people who are not Saudi women) comes to 'resemble the limited world of the image bank,' an 'ideologically prestructured world which is in harmony with consumerism' Machin (2004: 316) but abstracted from politics and everyday life.

There is nothing explicitly 'offensive' ('sexist', 'racist') about these images. What is troubling about them is the homogenous, unproblematically cheerful way they present the issue, erasing the complex social and historical conflicts surrounding it. The actual struggles and triumphs of Saudi women and the reality of the world in which they operate is never formulated.

The problem with these images is that they are disconnected from the real world. Due to the commercial incentives governing their production and consumption, , consequential events -- such as lifting the ban on Saudi women driving in Saudi Arabia - and important debates around issues like gender, culture and human rights themselves become commodities, limiting opportunities to engage in serious discussion of such matters and for the actual experiences of actual Saudi women to be part of that discussion. 


\section{References}

Abraham L and Appiah O (2006) Framing news stories: The role of visual imagery in priming racial stereotypes. Howard Journal of Communications, 17(3): 183-203.

Aiello G and Woodhouse A (2016) When corporations come to define the visual politics of gender: The case of Getty images. Journal of Language and Politics, 15(3): 352-368. doi:10.1075/jlp.15.3.08aie

Aiello et al. (2016) A critical genealogy of the Getty Images Lean In Collection: Researching the feminist politics of stock photography across representation, circulation

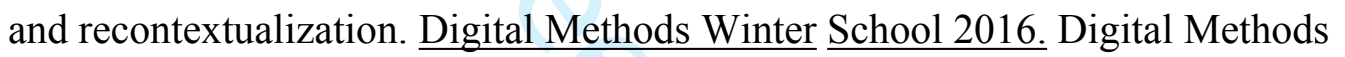
Initiative, University of Amsterdam. Retrived from https://wiki.digitalmethods.net/Dmi/WinterSchool2016CriticalGenealogyGettyImages LeanIn\#Initial_Data_Sets

Al-Malki A, David K, Suguru I and Kira D (2012) Arab Women in Arab News. Old Stereotypes and New Media. Doha, Qatar: Bloomsbury Qatar Foundation Publishing. Barthes R (1977) Image, Music, Text, London, Fontana.

Beaulieu J and Roberts M (Eds.) (2002) Orientalism's interlocutors: Painting, architecture, photography. Durham: Duke University Press Books.

Behdad A and Gartlan L (Eds.) (2013) Photography's orientalism: New essays on colonial representation. Los Angeles: Getty Research Institute.

Chasejarvis (2018) Getty images changes the stock photo game, again . From: https://www.chasejarvis.com/blog/getty-images-changes-the-stock-photo-game-again/ 
Chouliaraki L (2009) Journalism and the visual politics of war and conflict, In A. Stuart, (ed.) Routledge companion to news and journalism. London: Routledge, pp. 520-533.

Datta R, Joshi D, Li J and Wang J (2008) Image retrieval: Ideas, influences, and trends of the new age. ACM Computing Surveys (CSUR) 40(2):1-60. doi:10.1145/1348246.1348248

Datanyze (2020, Feb 23) Getty images vs. Shutterstock. Datanyze. https://www.datanyze.com/market-share/stock-images-providers/getty-images-vs$\underline{\text { shutterstock }}$

Eltantawy N (2013) From veiling to blogging: Women and media in the Middle East. Feminist Media Studies 13(5), 765-769.

Frosh P (2001) Inside the image factory: stock photography and cultural production. Media, Culture \& Society 23(5): 625-646.

Frosh P (2002) Rhetorics of the overlooked: On the communicative modes of stock advertising images. Journal of Consumer Culture 2(2): 171-196.

Frosh P (2003) The image factory: Consumer culture, photography and the visual content Industry. Oxford: Berg Publishers.

Goffman E (1987) Gender advertisements. New York ; Cambridge: Harper \& Row. Google (n.d.) How Search algorithms work. Google search. https://www.google.com/intl/en_uk/search/howsearchworks/algorithms/

Grossman P (n.d.) Genderblend. In Creative in Focus, Getty Images iBook. Retrieved from: http://stories.gettyimages.com/creative-focus-2015-visual-trends/

Halliday M A K (1985) Introduction to Functional Grammar, $1^{\text {st }}$ Edition. London: Edward Arnold. 
Introna L and Nissenbaum H (2000) Defining the web: The politics of search engines.Computer, 33(1): 54-62. DOI:10.1109/2.816269

Jackson N B (2011) Gulf Arabs: From caricatures to image managers. In S.D. Ross and P.M. Lester (ed.) Images that injure pictorial stereotypes in the media. Santa Barbara, CA: Praeger, pp. 337-349.

Jarbou, R. (2018). Know your enemy: the Saudi women's driving campaign from flyers and faxes to Youtube and hashtags. Feminist Media Studies, 18(2), 321-325.

Jones R H (2020) The rise of the pragmatic web: Implications for rethinking meaning and interaction. In C. Tagg \& M. Evans (Eds.), Message and medium: English language practices across old and new media. Amsterdam: De Gruyter Mouton, pp. 17-37

Jones R H (2021) The text is reading you: Teaching language in the age of the algorithm.

Linguistics and Education, 62, 100750. https://doi.org/10.1016/j.linged.2019.100750

Kamalipour Y R and Gerbner G (1997) The U.S. media and the Middle East: image and perception. Westport, CT: Praeger.

Kay M, Matuszek C and Munson S A (2015) Unequal Representation and Gender Stereotypes in Image Search Results for Occupations. In Proceedings of the 33rd Annual ACM Conference on Human Factors in Computing Systems (CHI '15). ACM, New York, NY, USA, 3819-3828. DOI: https://doi.org/10.1145/2702123.2702520

Kitch C (2009) The girl on the magazine cover: The origins of visual stereotypes in American mass media. Chapel Hill, NC: University of North Carolina Press.

Knox J (2007) Visual-verbal communication on online newspaper home pages. Visual Communication 6(1): 19-53.

Kress G (2003) Literacy in the New Media Age. London; New York: Routledge. Kress G and van Leeuwen T (2001) Multimodal Discourse. Bloomsbury USA. 
Kress G R and Van Leeuwen T (2006) Reading images : the grammar of visual design (2nd ed. ed.). London: Routledge.

MacDonald M (2006) Muslim women and the veil, Feminist Media Studies, 6 (1), 7-23.

Machin D (2004) Building the World's visual language: The increasing global importance of image banks in corporate media. Visual Communication 3(3): 316-336. doi:10.1177/1470357204045785

Machin D and Leeuwen T V(2007) Global media discourse: A critical introduction. London: Routledge.

Martin-Munoz G (2010) The Arab world's silent feminist revolution, Project Syndicate, 9 Dec. Available at: http://www.project-syndicate.org/commentary/the-arab-world-ssilent-feminist-revolution (17 Dec. 2012).

Mitchell W J (1994) The Reconfigured Eye: Visual Truth in the Post-photographic Era. Cambridge MA: MIT Press.

Newton J (2013) The Burden of Visual Truth: The Role of Photojournalism in Mediating Reality. London: Routledge.

Norris S and Jones R H (2005) Discourse in action: Introducing mediated discourse analysis Taylor and Francis.

Pariser E (2011) The filter bubble: What the internet is hiding from you. New York: Penguin Press.

Poindexter P M (2011) African-American images in the news: Understanding the past to improve future portrayals. In S.D. Ross and P.M. Lester (ed.) Images that injure pictorial stereotypes in the media. Santa Barbara, Calif: Praeger, pp. 107-120

Oberlo (2019) Search Engine Market Share in 2019. Oberlo. https://www.oberlo.co.uk/statistics/search-engine-market-share 
Otterbacher J, Bates J and D. Clough P (2017) Competent men and warm women: Gender stereotypes and backlash in image search results. In Proceedings of the $2017 \mathrm{CHI}$ Conference on Human Factors in Computing Systems, CHI 2017. 6620-6631.

Ross S D and Lester P M (2003) Images that injure: Pictorial stereotypes in the media (2nd edition). Westport, Conn: Praeger Publishers Inc.

Said E W (1979) Orientalism. New York: Vintage.

Sakr N (2008) Women and Media in Saudi Arabia: Rhetoric, Reductionism and Realities. British Journal of Middle Eastern Studies 35(3): 385-404.

Sekula A (1989) 'The Body and the Archive', in R. Bolton (ed.) The contest of meaning: Critical histories of photography, pp. 342-88. Cambridge, MA: MIT Press.

Scollon R (2001) Mediated discourse: The nexus of practice. London: Routledge Ltd. doi:10.4324/9780203420065

Scollon R (2008) Discourse itineraries: Nine processes of resemiotization. In V.K. Bhatia, J. Flowerdew, \& R.H. Jones (eds.) Advances in discourse studies. London: Routledge, pp. 243-254.

Thelwall M and Vaughan L (2004) Search engine coverage bias: Evidence and possible causes. Information Processing and Management 40(4): 693-707.

Thurlow C, Aiello G and Portmann L (2020) Visualizing teens and technology: A social semiotic analysis of stock photography and news media imagery. New Media \& Society 22(3): 528-549. doi:10.1177/1461444819867318

Van Leeuwen T (2008) Discourse and practice: New tools for critical analysis. New York: Oxford University Press.

VERBI Software (2019) MAXQDA 2020 [computer software]. Berlin, Germany: VERBI Software. Available from maxqda.com. 
Ward C G (2007) Stock images, filler content and the ambiguous corporate message. $M / C$ Journal 10(5). Retrieved from http://www.journal.media-culture.org.au/0710/04ward.php

Zelizer B (2005) Journalism through the camera's eye. In S. Allen (ed.) Journalism: Critical issues. Milton Keynes: Open University Press, pp. 167-176. 